\title{
Stability Characteristics of Wing Span and Sweep Morphing for Small Unmanned Air Vehicle: A Mathematical Analysis
}

\author{
Hafiz Muhammad Umer, ${ }^{1}$ Adnan Maqsood $\mathbb{D}^{1},{ }^{1}$ Rizwan Riaz, ${ }^{1}$ and Shuaib Salamat ${ }^{2}$ \\ ${ }^{1}$ Research Centre for Modeling \& Simulation, National University of Sciences \& Technology, Islamabad 44000, Pakistan \\ ${ }^{2}$ College of Aeronautical Engineering, National University of Sciences \& Technology, Islamabad 44000, Pakistan \\ Correspondence should be addressed to Adnan Maqsood; adnan@rcms.nust.edu.pk
}

Received 11 March 2020; Revised 22 May 2020; Accepted 6 June 2020; Published 3 July 2020

Academic Editor: Daniela Addessi

Copyright (c) 2020 Hafiz Muhammad Umer et al. This is an open access article distributed under the Creative Commons Attribution License, which permits unrestricted use, distribution, and reproduction in any medium, provided the original work is properly cited.

\begin{abstract}
Morphing aircraft are the flight vehicles that can reconfigure their shape during the flight in order to achieve superior flight performance. However, this promising technology poses cross-disciplinary challenges that encourage widespread design possibilities. This research aims to investigate the flight dynamic characteristics of various morphed wing configurations that can be incorporated in small-scale UAVs. The objective of this study was to analyze the effects of in-flight wing sweep and wingspan morphing on aerodynamic and flight stability characteristics. Longitudinal, lateral, and directional characteristics were evaluated using linearized equations of motion. An open-source code based on Vortex Lattice Method (VLM) assuming quasi-steady flow was used for this purpose. Trim points were identified for a range of angles of attack in prestall regime. The aerodynamic coefficients and flight stability derivatives were compared for the aforementioned morphing schemes with a fixed-wing counterpart. The results indicated that wingspan morphing is better than wing sweep morphing to harness better aerodynamic advantages with favorable flight stability characteristics. However, extension in wingspan beyond certain limits jeopardizes the advantages. Dynamically, wingspan and sweep morphing schemes behave in an exactly opposite way for longitudinal modes, whereas lateral-directional dynamics act in the same fashion for both morphing schemes. The current study provided a baseline to explore the advanced flight dynamic aspects of employed wing morphing schemes.
\end{abstract}

\section{Introduction}

The role of Unmanned Air Vehicles (UAVs) in unconventional and asymmetric military roles as well as diversified civil environments is on the rise. UAVs are designed to meet conflicting mission requirements with dynamic on-board reconfiguration capabilities. The conventional fixed-wing aircraft design puts severe flight limitations to operate in a diverse set of mission requisites. Wing morphing is attributed as a potential approach to significantly affect the aerodynamic characteristics of a flying vehicle during flight $[1,2]$. The motivation behind wing morphing comes from the birds that change their wings' configuration to attain suitable aerodynamic profile for various flight conditions $[3,4]$. Wing morphing technology, although not new, in conjunction with smart materials has renewed the interest of researchers to look for versatile morphing configurations [5-7]. It refers to the changing wing planform by varying wing geometric parameters like span, sweep angle, dihedral angle, chord length, wing twist, and airfoil shape modification [8-10]. Among these versatile morphing schemes, wingspan, sweep angle, and wing dihedral are the most influential wing parameters toward the performance and stability of the aircraft [11-13].

Wingspan and sweep angle mainly affect the wing planform. These are the most important morphing parameters that can greatly affect the aircraft's flight dynamics. Both wingspan and sweep angle can be adjusted to control the wing aspect ratio in order to modify lift-to-drag ratio, lift-curve slope, the inertia of the aircraft, and other forces depending on the wing area. Thus, both the performance and stability of the aircraft can be improved by increasing the wing aspect ratio 
[14]. For span variation, inflatable telescopic wing design is normally a preferred choice as it has the ability to undergo a $114 \%$ change [15] in aspect ratio while supporting aerodynamic loads. Blondeau et al. [15] performed a study of the inflatable telescopic wing with three different degrees of extension in the wind tunnel and compared it with the fixed wing of the same wingspan. Their results conclude that a high lift-to-drag ratio is achievable by extending the telescopic wing but observed less lift-to-drag ratio compared with the fixed wing of the same span as parasite drag increases due to the seams between the wing sections.

Similarly, an increase/decrease in sweep angles causes corresponding changes in aerodynamic parameters [16]. Wings with a higher sweep angle are more advantageous in attaining the highest maximum speed (dash) while the smaller wing sweep angle was more suitable for higher range and endurance for loiter/reconnaissance missions. Recently, a performance and flight dynamic study of a variable-sweep wing was conducted by Kong [17] and Chong [18], respectively. Kong performed trim calculations for specific velocities and angles of attack to discuss various performance and stability characteristics while Chong investigated the same stuff performing trim analysis for particular cruise speeds and altitudes. Both these researchers outlined suitable mission paths for optimal performance according to their respective morphing schemes. Prabhakar et al. [19] discussed the longitudinal dynamics of morphing aircraft with variable wingspan and sweep by trimming the aircraft for specific speeds and altitudes. Computation of aerodynamic coefficients and stability analysis were performed using Vortex Lattice Method (VLM) code in researches referenced as [17-19].

Wing morphing is a complex phenomenon and invokes interdisciplinary challenges. Along with aerodynamic feasibility, various structural, mechanical, and flight dynamic stability challenges have made this technology more dependent and complicated. In order to change the wing shape, an appropriate mechanism is required which best suits the aerodynamic profile of the aircraft. Usually, actuators are required in the internal mechanism to change the wing shape. This mechanism must be covered with flexible or sliding aerodynamic surfaces capable of having load-transfer attachments. A complicated mechanism of series of actuators and flexible materials is required to construct a morphing wing. Actuator requirements for a controlled morphing aircraft were presented by Inman [20] which discusses the design mechanism for the range of motion, concerns about binding and friction, the effects of wing structural deformability under load, and the control of the actuator stroke under load. Generally, a successful wing morphing system must be able to overcome the aerodynamic load shifting (due to the change in aerodynamic center of aircraft during morphing) as well as the weight penalty of added mechanical systems. Tarnowski and Goetzendorf-Grabowski [21] and Tarnowski [22] presented a novel concept of wing morphing that circumvented the issue of elastic deformation. The interesting part of the study was its validation through wind tunnel testing, which is generally not attempted during morphing studies. An appropriate structural design is essential which can withstand the aerodynamic load conditions along with morphing capabilities. Therefore, weight penalty is a side challenge for the development of small morphing wing aircraft.

The improvement in aerodynamic performance with inflight morphing results in altering flight dynamic characteristics of UAVs [23-28]. Small UAVs are characterized by low moment of inertias. Any change in the geometric configuration results in pronounced variations in the flight stability characteristics. This warrants the need of investigation of variation in flight stability characteristics as a result of wing morphing. Aircraft fight stability concerns are typically assumed to be regulated by Automatic Flight Control System (AFCS). This assumption has made several sophisticated designs unfeasible for the fact that control architectures need an underlying dynamic model. These issues are especially aggravated during the transitional morphing phase. Therefore, accurate prediction about the dynamic efficiency of aircraft, morphing limits, and reliance of aircraft's stability on wing morphing parameters is essential during the preliminary design stage. The stability analysis of a small-scale UAV under two different wing symmetric morphing schemes (variable span and sweep angle) is the contribution of the present work.

In this paper, geometric details of UAV and mathematical model used for the dynamic evaluation are discussed first. It is followed by aerodynamic data generation using panel methods. Subsequently, the results are discussed in terms of trim conditions, static stability, and aircraft dynamic modes for both (variable wingspan and sweep angle) morphing schemes. The current research is aimed at the feasibility study of different morphing concepts for a smallscale UAV from flight dynamic perspective.

\section{Problem Formulation}

2.1. Geometric Modeling. The aircraft considered for the dynamic evaluation is a standard wing-tail configuration made up of extended polypropylene with carbon-fiber rods used for reinforcement. The model has a fuselage length and wingspan of $0.84 \mathrm{~m}$ and $1 \mathrm{~m}$, respectively. The aspect ratio of the wings is 4.31 . The model of aircraft with baseline and extreme geometric configurations is overlaid in Figure 1. Typical dimensional attributes of baseline configuration are shown in Table 1. The baseline configuration has no sweep and wingspan of $1.00 \mathrm{~m}$. The wing area used to calculate aerodynamic coefficients is $0.24 \mathrm{~m}^{2}$ of baseline configuration. The leading edges of wing, elevator, and center of gravity are located at $0.12 \mathrm{~m}, 0.7 \mathrm{~m}$, and $0.2 \mathrm{~m}$, respectively.

For wingspan and sweep morphing, various mechanisms are suggested in different studies [15, 29-35]. For span morphing, the existing wingspan of $1 \mathrm{~m}$ can go up to $1.4 \mathrm{~m}$. For sweep morphing, the wings can be swept between $0^{\circ}$ and 


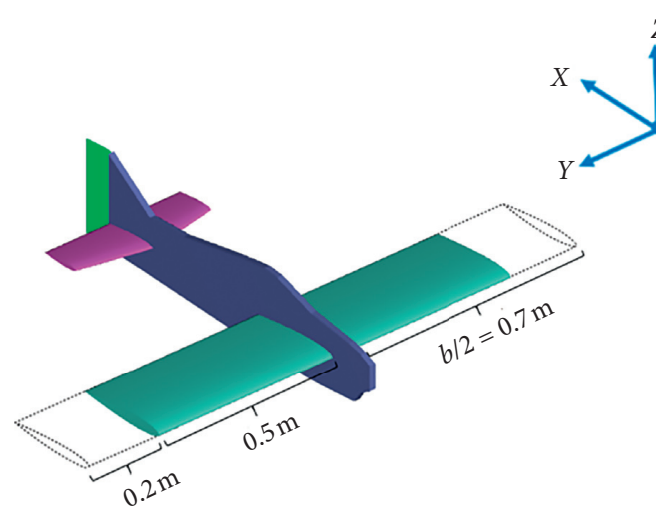

(a)

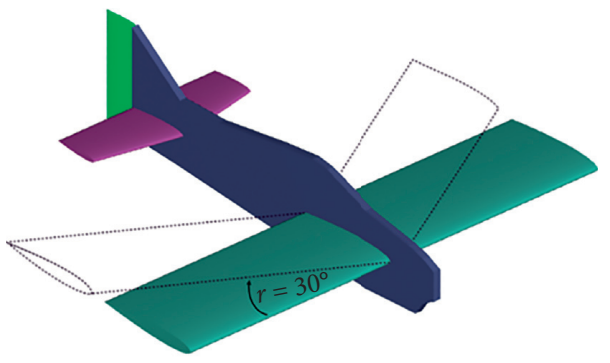

(b)

Figure 1: Aircraft baseline model with extreme morphing states: span morphing (a) and sweep morphing (b).

TABLE 1: Model parameters.

\begin{tabular}{lc}
\hline Parameter name & Value \\
\hline Wingspan & $1.00 \mathrm{~m}$ \\
Wing chord & $0.24 \mathrm{~m}$ \\
Wing area & $0.24 \mathrm{~m}^{2}$ \\
Aspect ratio & 4.17 \\
Taper ratio & 1.0 \\
Wing sweep $\left(^{\wedge}\right)$ & $0^{\circ}$ \\
Wing dihedral & $0^{\circ}$ \\
Wing LE position & $(0.12,0,0) \mathrm{m}$ \\
Wing, elevator airfoil & NACA 0012 \\
Fuselage length & $0.84 \mathrm{~m}$ \\
Elevator LE position & $(0.7,0,0.01) \mathrm{m}$ \\
Elevator root chord & $0.14 \mathrm{~m}$ \\
Elevator tip chord & $0.1 \mathrm{~m}$ \\
Elevator area & $0.05 \mathrm{~m}^{2}$ \\
Vertical fin area & $0.02 \mathrm{~m}^{2}$ \\
Tail volume & 0.054 \\
Total mass & $0.495 \mathrm{~kg}$ \\
Center of gravity & $(0.2,0,0.1) \mathrm{m}$ \\
\hline
\end{tabular}

$30^{\circ}$. The effect of span morphing on change in the center of gravity was calculated and found to be negligible. Similarly, the effect of sweep morphing on the change in wing area was negligible.

2.2. Aerodynamic and Flight Dynamic Modeling. Various analytical models and computational techniques [36-39] with varying degrees of accuracy and computation time can be used to model the aircraft's aerodynamics. In the present work, such an aerodynamic model was required which can predict forces and moments of the aircraft in less computational time. Thus, Vortex Lattice Method (VLM) [39] is assumed to be the best choice of aerodynamic modeling at the preliminary design phase. Numerical models of aircraft aerodynamics for various wing configurations were developed using steady VLM. For dynamic modeling, linearized six Degree of Freedom (6-DoF) rigid body equations of motion framework were used to accomplish stability and control analysis. Underlying design configurations were built and analyzed through an open source three-dimensional VLM code named XFLR5 $[40,41]$. In order to simplify the aircraft dynamics, the effects of morphing motion are neglected assuming quasi-static morphing. Therefore, aerodynamic and stability analyses were performed by morphing aircraft's wings from one configuration to the other enabling a simple prototype to be built.

Aerodynamic evaluation of the UAV was performed at $15 \mathrm{~m} / \mathrm{s}$ in the prestall regime (angles of attack varied from $0^{\circ}$ to $20^{\circ}$ ). The effect of span and sweep morphing on the coefficient of lift, drag, and pitching moment is shown in Figures 2-4. The wing area is kept the same during computation of aerodynamic coefficients to baseline value, that is, $0.24 \mathrm{~m}^{2}$. It should be noted that the stall characteristics cannot be accurately captured due to the limitation of VLM. Therefore, the current findings are only valid in the low angle of the attack range. The increase in the wingspan result is nominal increase in coefficient of lift; however, the minimum change is observed due to the wing sweep variation. For the coefficient of drag, the effects of sweep and span variation are not significant. It should be noted that various studies primarily focus on aerodynamic evaluation of morphing behavior; however, it will be seen ahead in the paper that morphing has more pronounced effect on stability than aerodynamic characteristics.

Pitching moment coefficient, a primary indicator for longitudinal static stability, is plotted in Figure 4 for both morphing schemes. Wingspan extension results in a decrease in longitudinal static stability whereas the increase in sweep angle increases longitudinal static stability. The pitching moment is computed around the center of gravity of aircraft. For span morphing case, a stability reversal around $15^{\circ}$ angle of attack is observed for the maximum 


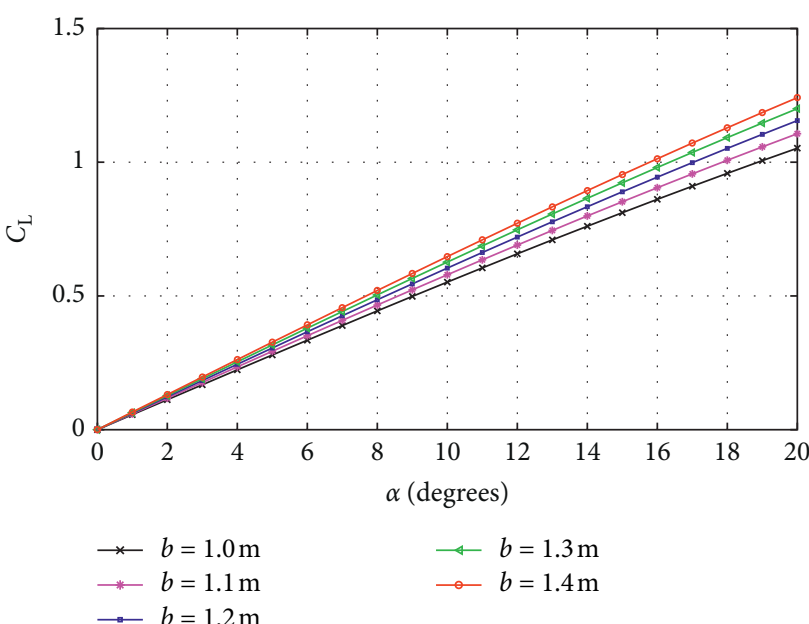

(a)

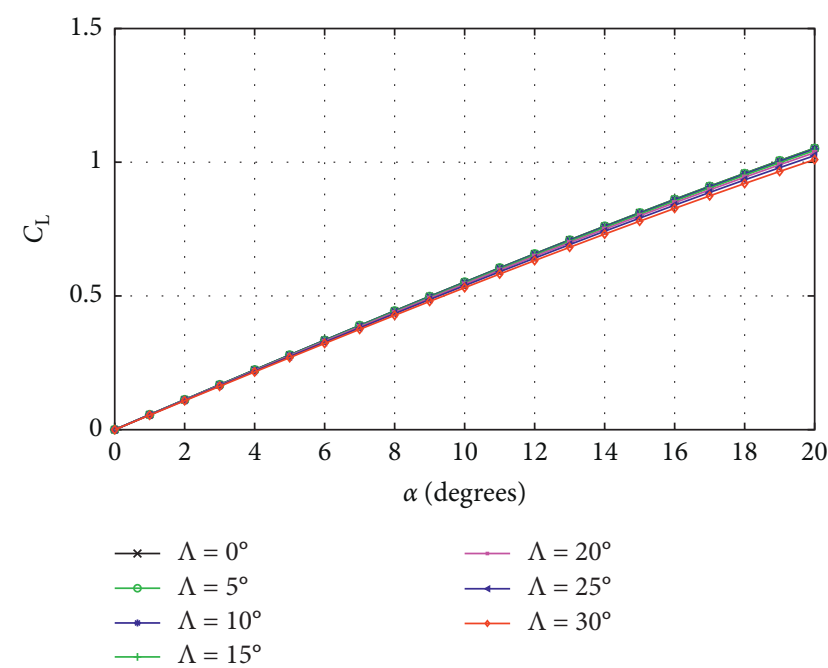

(b)

Figure 2: Lift coefficients for wingspan (a) and wing sweep (b) morphing at fixed speed with varying angles of attack.

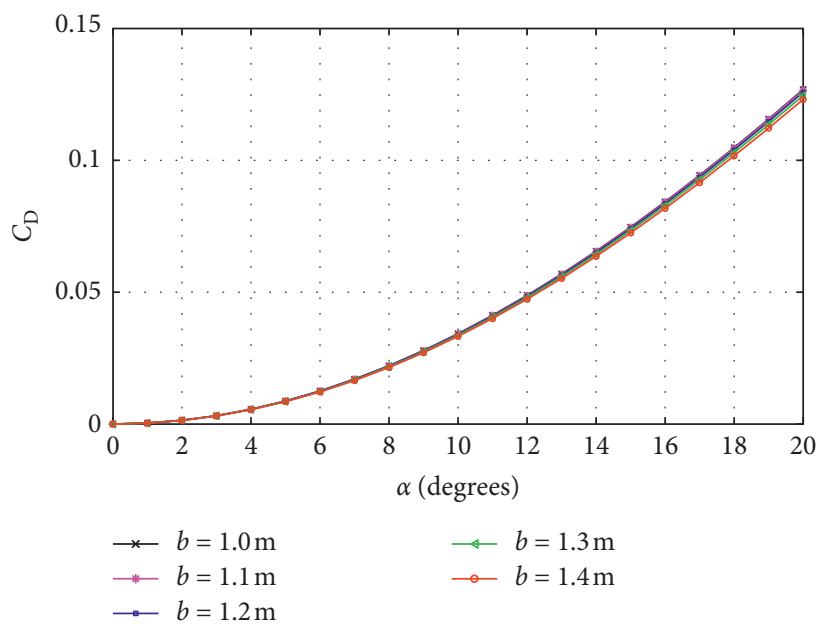

(a)

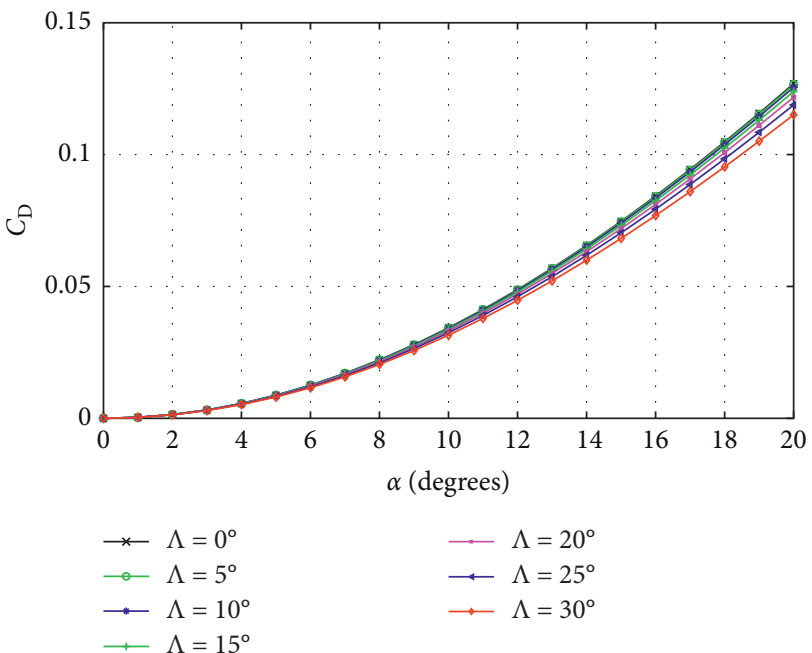

(b)

Figure 3: Drag coefficients for wingspan (a) and wing sweep (b) morphing at fixed speed with varying angles of attack.

span configuration. This suggests that the span moves a neutral point of the aircraft forward (toward aircraft nose) whereas sweep moves a neutral point of the aircraft backward.

The standard practice to establish the flight dynamic model of a conventional aircraft is to derive rigid body equations of motion which can effectively predict aircraft's translational and rotational dynamics [42]. In this paper, UAV dynamics is represented by an elaborate 6-DoF model (refer to equations (2) and (3)) which is linearized under the assumptions of steady state flight conditions.
The said model is conveniently expressed in the form of state space as

$$
\dot{x}=\mathbf{A x}+\mathbf{B u},
$$

where $\mathbf{A}$ is the system matrix, $\mathbf{x}$ is the state vector, containing variables describing the state of the system, $\mathbf{B}$ is the input matrix, and $\mathbf{u}$ is the input vector, containing input variables (usually thrust and control surfaces deflections). Lateral/ directional controls (ailerons and rudder) remain neutral throughout the analysis; therefore, input vector is zero for lateral-directional dynamics: 


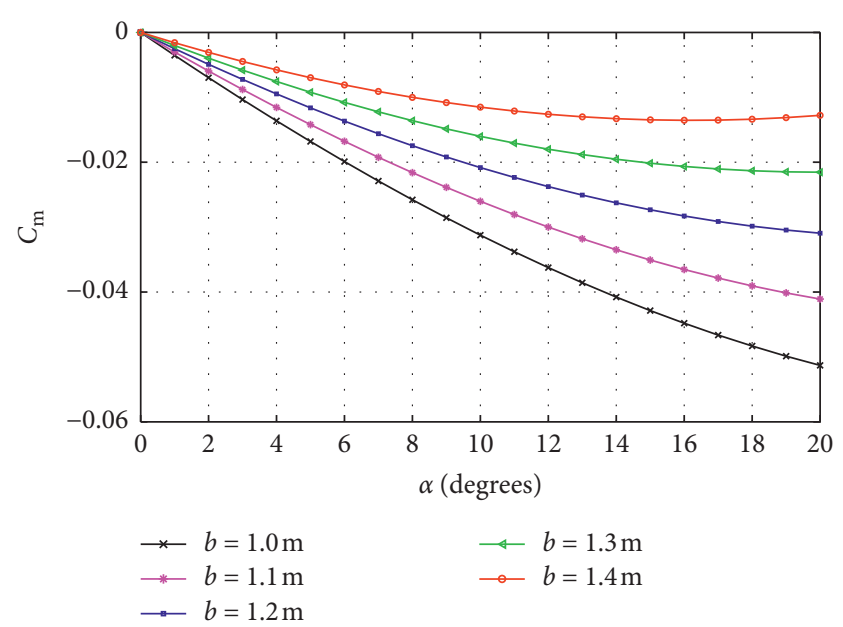

(a)

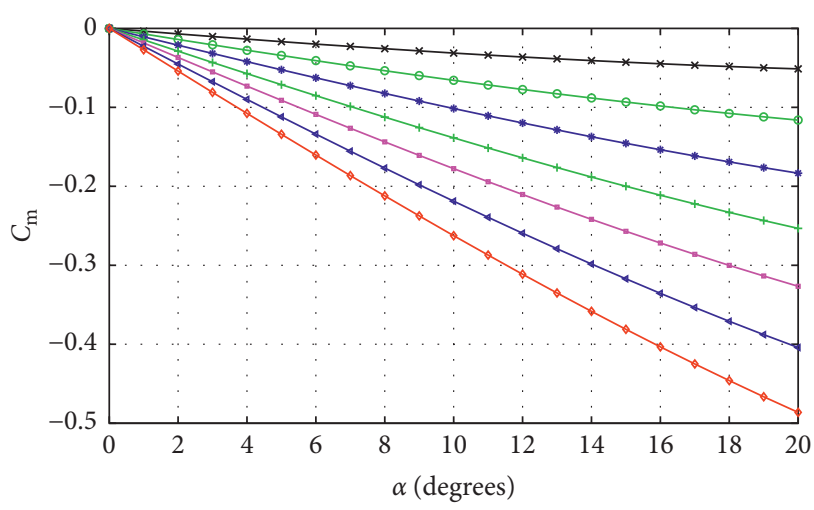

$$
\begin{aligned}
& \rightarrow \Lambda=0^{\circ} \\
& \rightarrow \Lambda=5^{\circ} \\
& \rightarrow \Lambda=10^{\circ} \\
& \rightarrow \Lambda=15^{\circ}
\end{aligned}
$$$$
\begin{aligned}
\longrightarrow \Lambda & =20^{\circ} \\
\longleftarrow & =25^{\circ} \\
\multimap & =30^{\circ}
\end{aligned}
$$

(b)

FIGURE 4: Pitching moment (with respect to CG) coefficients for wingspan (a) and wing sweep (b) morphing at fixed speed with varying angles of attack.

$$
\begin{aligned}
& {\left[\begin{array}{c}
\dot{u} \\
\dot{w} \\
\dot{q} \\
\dot{\theta}
\end{array}\right]=\left[\begin{array}{ccc}
\frac{X_{u}}{m} & \frac{X_{w}}{m} & -g \cos \theta_{0} \\
\frac{Z_{u}}{m-Z_{\dot{w}}} & \frac{Z_{w}}{m-Z_{\dot{w}}} & \frac{-m g \sin \theta_{0}}{m-Z_{\dot{w}}} \\
\frac{1}{I_{y y}}\left(M_{u}+\frac{M_{\dot{w}} Z_{u}}{m-Z_{\dot{w}}}\right) & \frac{1}{I_{y y}}\left(M_{w}+\frac{M_{\dot{w}} Z_{w}}{m-Z_{\dot{w}}}\right) & \frac{1}{I_{y y}}\left(M_{q}+\frac{M_{\dot{w}}\left(Z_{q}+m u_{0}\right)}{m-Z_{\dot{w}}}\right) \\
0 & -\frac{M_{\dot{w}} m g \sin \theta_{0}}{I_{y y}\left(m-Z_{\dot{w}}\right)} \\
0 & 1
\end{array}\right]\left[\begin{array}{c}
u \\
w \\
\theta
\end{array}\right]} \\
& +\left[\begin{array}{c}
\frac{X_{\delta_{e}}}{m} \\
\frac{Z_{\delta_{e}}}{m-Z_{\dot{w}}} \\
\frac{1}{I_{y y}}\left(M_{\delta_{e}}+\frac{M_{\dot{w}} Z_{\delta_{e}}}{m-Z_{\dot{w}}}\right) \\
0
\end{array}\right]\left[\delta_{e}\right], \\
& {\left[\begin{array}{c}
\dot{v} \\
\dot{p} \\
\dot{r} \\
\dot{\phi}
\end{array}\right]=\left[\begin{array}{cccc}
\frac{Y_{v}}{m} & \frac{Y_{p}}{m} & \left(\frac{Y_{r}}{m}-u_{0}\right) & g \cos \theta_{0} \\
\frac{L_{v}}{I_{x}^{*}}+I_{x z}^{*} N_{v} & \frac{L_{p}}{I_{x}^{*}}+I_{x z}^{*} N_{p} & \frac{L_{r}}{I_{x}^{*}}+I_{x z}^{*} N_{r} & 0 \\
I_{x z}^{*} L_{v}+\frac{N_{v}}{I_{z}^{*}} & I_{x z}^{*} L_{p}+\frac{N_{p}}{I_{z}^{*}} & I_{x z}^{*} L_{r}+\frac{N_{r}}{I_{z}^{*}} & 0 \\
0 & 1 & \tan \theta_{0} & 0
\end{array}\right]\left[\begin{array}{l}
v \\
p \\
r \\
\phi
\end{array}\right],}
\end{aligned}
$$


where $I_{x}^{*}=\left(I_{x x} I_{z z}-I_{x z}^{2}\right) / I_{z z} ; \quad I_{z}^{*}=\left(I_{x x} I_{z z}-I_{x z}^{2}\right) / I_{x x}$; $I_{x z}^{*}=I_{x z} /\left(I_{x x} I_{z z}-I_{x z}^{2}\right)$. Using the following relations, the angle of attack $\alpha$ instead of vertical velocity $w$ and side slip angle $\beta$ instead of side velocity $v$ are approximated as longitudinal and lateral-directional state variables, respectively:

$$
\begin{gathered}
\alpha \approx \frac{w}{u_{0}} ; \\
\beta \approx \frac{v}{u_{0}} .
\end{gathered}
$$

2.2.1. Aircraft Dynamic Modes. The UAV under discussion can typically exhibit five types of dynamic responses toward longitudinal and lateral-directional perturbations which include three oscillatory (short period, phugoid, and Dutch roll) modes and two nonoscillatory (roll subsidence and spiral) modes. Frequency and damping of respective modes are approximated using the relations as summarized in Table $2[43,44]$.

In order to relate eigenvalues with the flying characteristics, the period of oscillations, $T$, time to half the amplitude, $T_{1 / 2}$, and time to double the amplitude, $T_{2}$, are also calculated for oscillatory modes $[45,46]$. The real part of the eigenvalue is denoted by $\eta$ and imaginary part by $\omega$. It should be noted that the oscillatory modes are phugoid, short period, and Dutch roll only:

$$
\begin{aligned}
& T \approx \frac{2 \pi}{\omega}, \\
& T_{1 / 2}=-\frac{\ln (2)}{\eta}, \quad \text { for } \eta<0 \text {, } \\
& T_{2}=\frac{\ln (2)}{\eta}, \quad \text { for } \eta>0 \text {. }
\end{aligned}
$$

The time to double or half the amplitude, $T_{1 / 2}$ and $T_{2}$, for periodical modes, spiral and roll subsidence, is also calculated through equation (6). Aerodynamic forces and moments' database is developed for all morphing states. Using 6-DOF dynamic model presented in equations (2) and (3), both longitudinal and lateral-directional dynamics are evaluated and stability derivatives are estimated based on computed aerodynamic forces. For different span and sweep angle variations, various trim states across a spectrum of angles of attack in prestall regime were evaluated for each morphing scheme. Elevator trim deflections and trim velocities are explored to investigate the equilibrium flight conditions. Both static and dynamic stability characteristics are then analyzed based on linearization about trim states for each morphing scheme.

\section{Results and Discussion}

3.1. Trim Conditions for Wingspan and Sweep Morphing. In Figure 5, variations in elevator trim deflections are plotted over a range of trim angles of attack for both wingspan and sweep morphing schemes. Significantly reduced elevator control effort and a resulting decrease in elevator authority to stabilize the aircraft can be observed by increasing wingspan (refer to Figure 5(a)). The behavior manifests desirable feature of wingspan morphing. Moreover, elevator deflection requirements increase with the trim angle of attack; however, that is a trivial requirement at high angle of attack. Wing sweep morphing invokes two aerodynamic phenomena and reduces effective moment arm for elevator due to aft center of pressure movement and alter the spanwise lift distribution pattern on the wings. Therefore, the significant increase in elevator control effort by wing sweep morphing is indicated (Figure 5(b)).

Figure 6 suggests that, for a particular wingspan, trim angle of attack reduces proportionally with trim velocity. On the contrary, the increase in wingspan reduces trim velocity requirements for the same trim angle of attack. It can be attributed to reduced thrust requirements as additional lift is provided from increased wing area. This argument can be corroborated from Figure 2(a) where higher wingspan results in higher coefficient of lift. The increment is a result of increase in effective aspect ratio of the wings. In comparison with wingspan morphing, a significant increase in overall trim velocity can be observed for swept wings' configurations (refer to Figure 6(b)). The increase in sweep angle typically results in a decrease in lift coefficient (refer to Figure 2(b)). Therefore, the trim velocity at lower angles of attack is higher for high swept configurations.

3.2. Longitudinal Static Stability. A comparison of aircraft longitudinal static stability for both morphologies is presented in Figure 7. Both morphing schemes exhibit longitudinally statically stable attributes over the entire range of trim states. However, it decreases with the increase in wingspan and significantly declines for $1.4 \mathrm{~m}$ span configuration (Figure 7(a)). In case of sweep morphing, substantially increasing pitch stiffness signifies the increase in longitudinal static stability for swept wings' configurations (refer to Figure 7(b)). These results are substantively associated with the neutral point movement and, hence, static margin of the aircraft that vary with the change in wings' configuration. For span morphing, CG variation is trivial. However, in Figure 8(a), the downward shift along the spanwise curves depicts the aft neutral point movement toward CG, thus resulting in a decrease in static margin. A reversing movement of neutral point (toward CG) along the trim angles of attack can be observed for $1.4 \mathrm{~m}$ wingspan configuration. This can be correlated with the decrease in longitudinal static stability in Figure 7(a). Wing sweep morphing is followed by the change in neutral point due to wings' configuration. Figure 8(b) shows a reasonable increase in the resulting static margin due to the aft neutral point movement for sweep morphing. This variation of static margin justifies the trend of pitch stiffness of sweep morphing as shown in Figure 7(b). For sweep morphing, the center of gravity moves from $0.2 \mathrm{~m}$ position at $0^{\circ}$ sweep to $0.236 \mathrm{~m}$ position at $30^{\circ}$ sweep. The shift in CG is catered in static margin calculation. 
TABle 2: Aircraft dynamic modes approximation.

\begin{tabular}{lcccc}
\hline Mode name & Frequency & Damping & Mode name & Damping \\
\hline Short period & {$\left[M_{q} Z_{w}-M_{\alpha}\right]^{1 / 2}$} & $-\left[M_{q}+u_{0} M_{\dot{w}}+Z_{w}\right] / 2 \omega_{s p}$ & Roll subsidence & $L_{p}$ \\
Phugoid & $\sqrt{2} g / u_{0}$ & $1 / \sqrt{2}(L / D)$ & Spiral & $\left(N_{r}-N_{v}\left(L_{r} / L_{v}\right)\right)$ \\
Dutch roll & $\sqrt{\left(u_{0} N_{v}+Y_{v} N_{r}-N_{v} Y_{r}\right)}$ & $N_{r}+y_{v}$ & \\
\hline
\end{tabular}

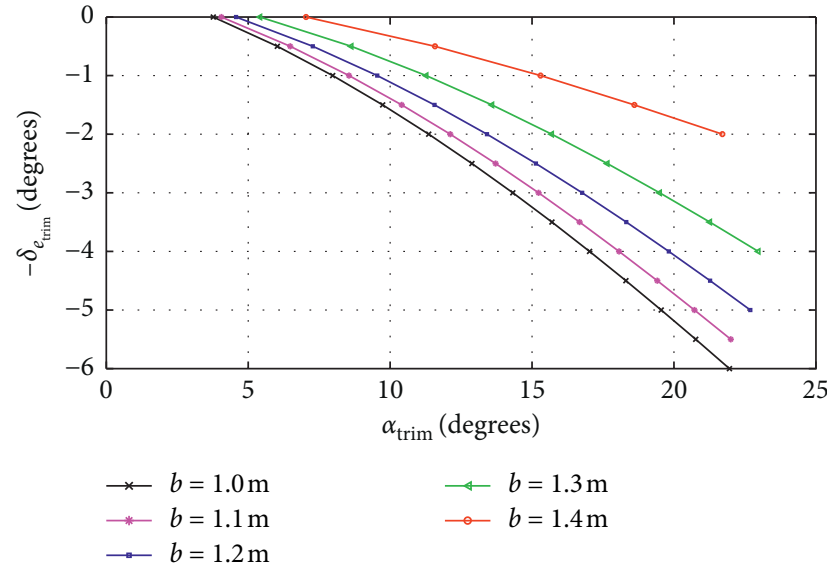

(a)

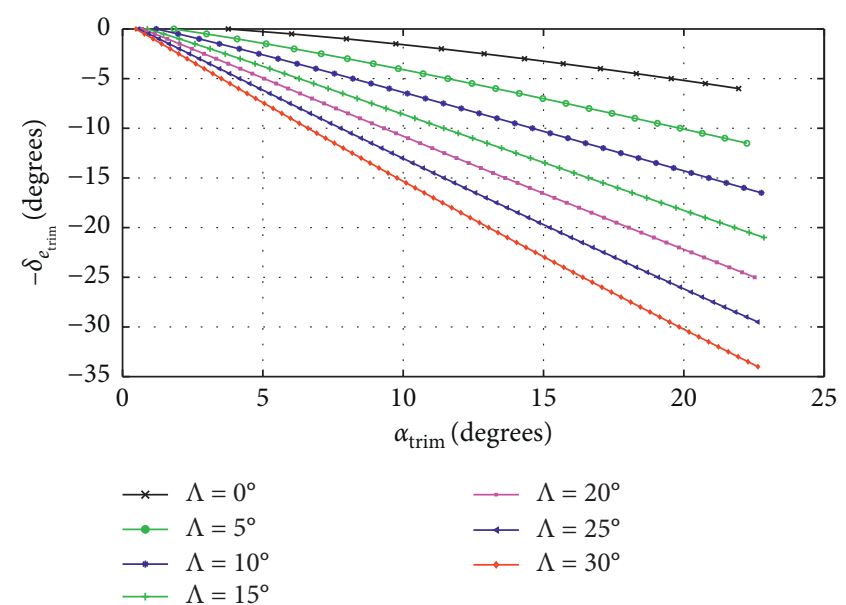

(b)

FIGURE 5: Elevator trim deflection for wingspan (a) and wing sweep (b) morphing.

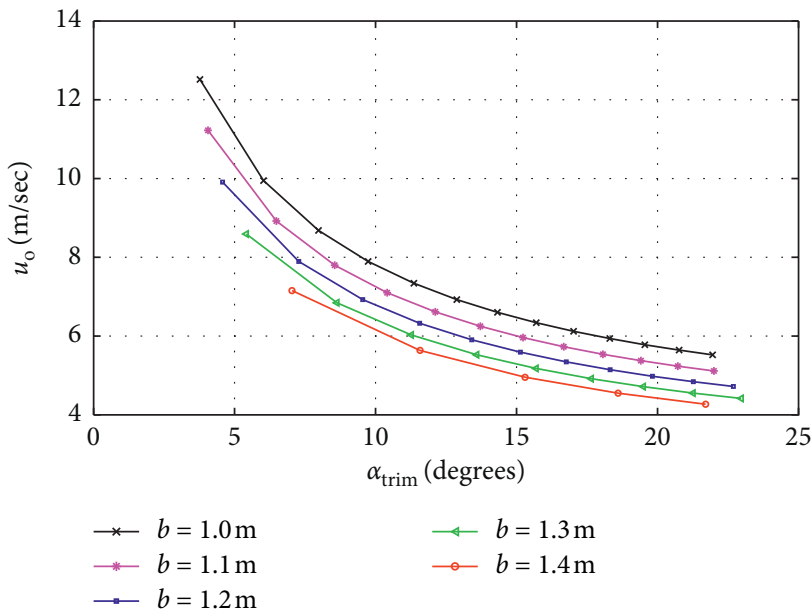

(a)

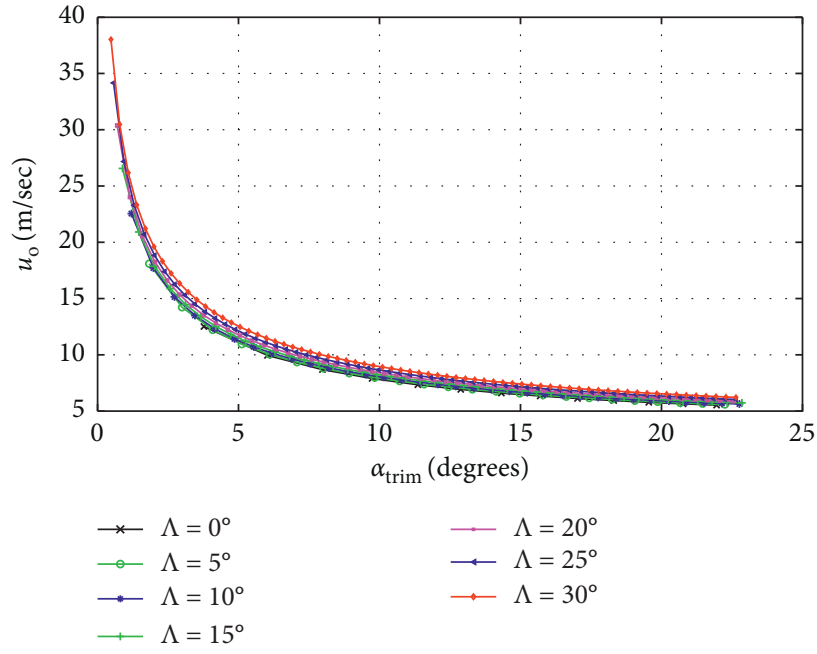

(b)

Figure 6: Trim velocity for wingspan (a) and wing sweep (b) morphing.

3.3. Lateral-Directional Static Stability. Lateral and directional static stabilities are determined by the signs of $C_{l_{\beta}}$ (coefficient of rolling moment due to sideslip) and $C_{\mathrm{n}_{\beta}}$ (coefficient of yawing moment due to sideslip), respectively. For span morphing, $C_{\mathrm{l}_{\beta}}$ remains positive for all the configurations indicating a benign nature of instability as shown in Figure 9(a). Laterally unstable behavior for wingspan morphing is probably due to the absence of wing dihedral. Sweep morphing, however, plays an imperative role in providing lateral stability. Figure 9(b) represents a significant increase in aircraft lateral static stability along the trim states with the increase in wing sweep angle. This is mainly due to the established fact that wing sweep angle provides an amount of effective dihedral as given by

$$
C_{l_{\beta}}=-\frac{1+2(\mathrm{TR})}{3(1+\mathrm{TR})} C_{\mathrm{L}} \tan \Lambda
$$

where TR is the wing tapper ratio, $C_{\mathrm{L}}$ is the lift coefficient, and $\Lambda$ is the wing sweep angle. Directional static stability of this particular aircraft is aided by its unconventional 


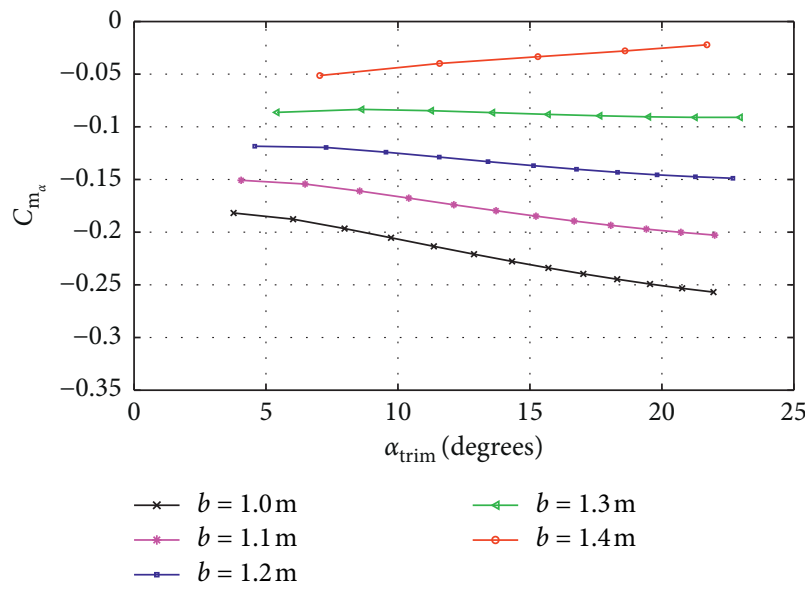

(a)

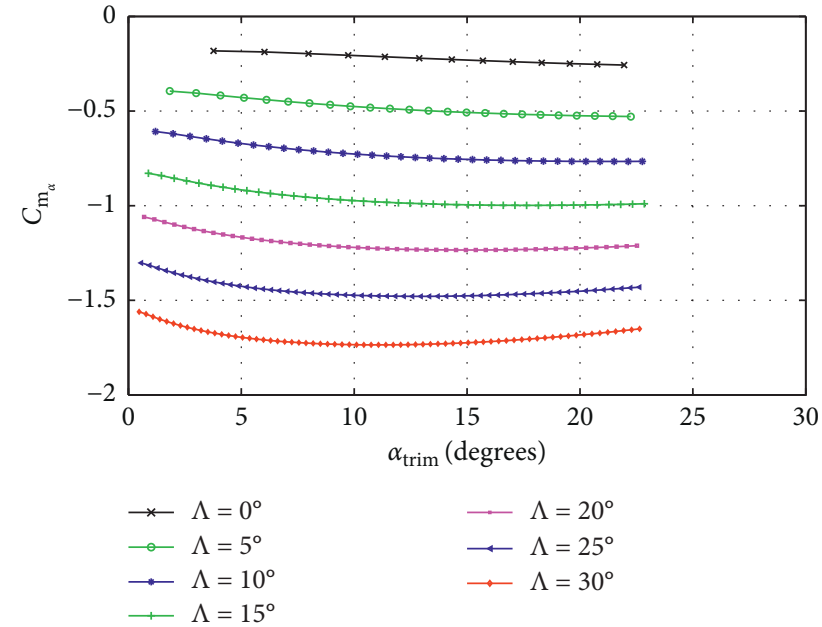

(b)

Figure 7: Pitch stiffness for wingspan (a) and wing sweep (b) morphing.

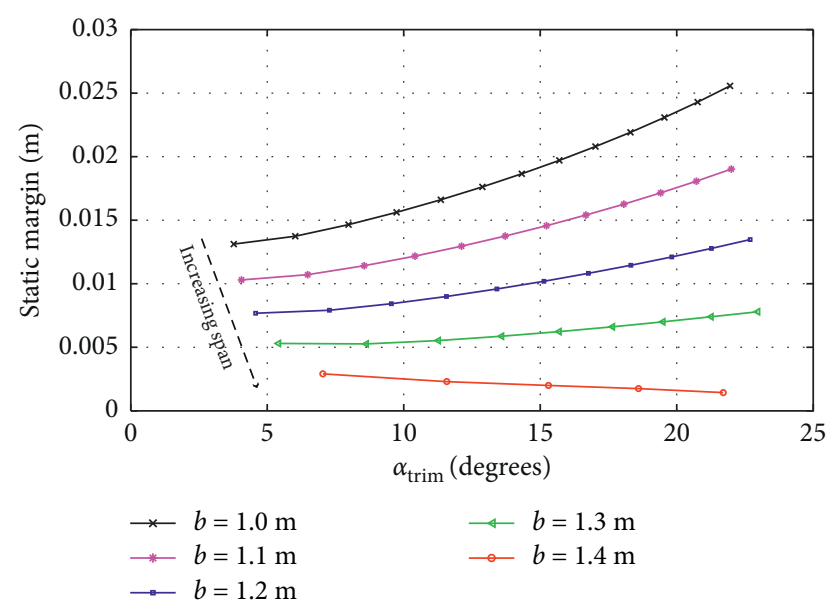

(a)

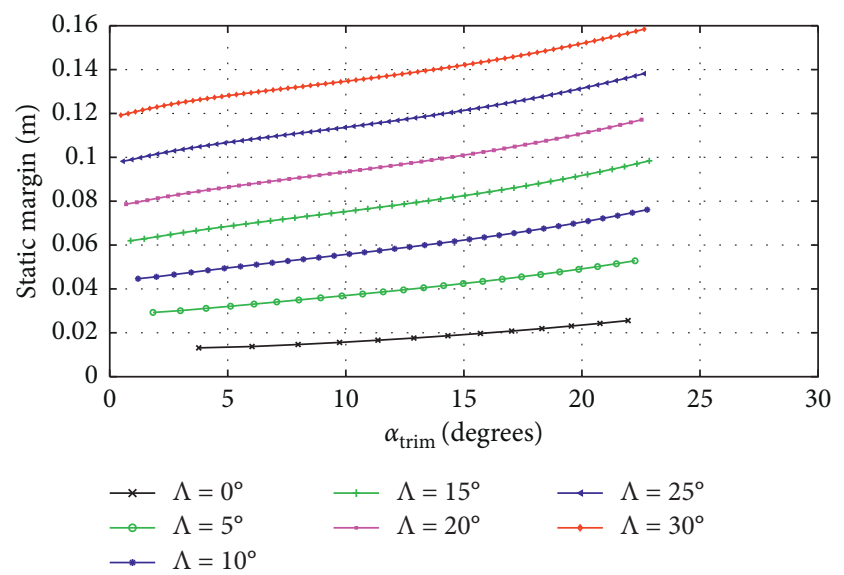

(b)

FIGURE 8: Static margin variation for wingspan morphing (a) and wing sweep morphing (b).

vertically extended fuselage shape and high rudder area. The increase in wingspan results in reducing the aircraft directional static stability as depicted in Figure 10(a). Directional static stability also reduces with the increase in trim angle of attack for wingspan morphing because at high angles of attack, rudder effectiveness gets jeopardized. Wing sweep morphing substantially contributes toward aircraft directional static stability particularly at higher trim angles of attack. Figure 10(b) indicates the declivity in directional stability with the increasing trim angles of attack. Eventually, a stability reversal followed by the exponential increase in directional static stability can be observed for all the configurations having wing sweep angle greater than $10^{\circ}$. These results can also be mathematically correlated. If an aircraft with swept wings at $\Lambda$ degrees, flying in steady level flight conditions operating at an angle of attack $\alpha$ with a velocity $u$, experiences a horizontal disturbance leading to a sideslip angle $\beta$, then the effective angle of attack $\alpha_{w}$ and dynamic pressure $q_{o_{w}}$ on the wings are given by

$$
\begin{aligned}
\alpha_{w} & = \pm \alpha \beta \sec \Lambda \tan \Lambda, \\
\alpha_{o_{w}} & =\frac{1}{2} \rho u^{2} \pm \alpha \beta \sec \Lambda \tan \Lambda,
\end{aligned}
$$

where the positive sign is for starboard wing and the negative sign for portside wing. A sideslip disturbance will increase the local angle of attack and dynamic pressure on the exposing wingspan whereas a reverse would happen on the other wing. As a consequence, the difference in lift and drag on both wings will be pronounced and generate a restoring yawing moment in the direction opposite the sideslip. This makes the aircraft directionally stable. A laterally perturbed aircraft rolling in one direction will naturally sideslip in the same direction. The angle of attack and dynamic pressure 


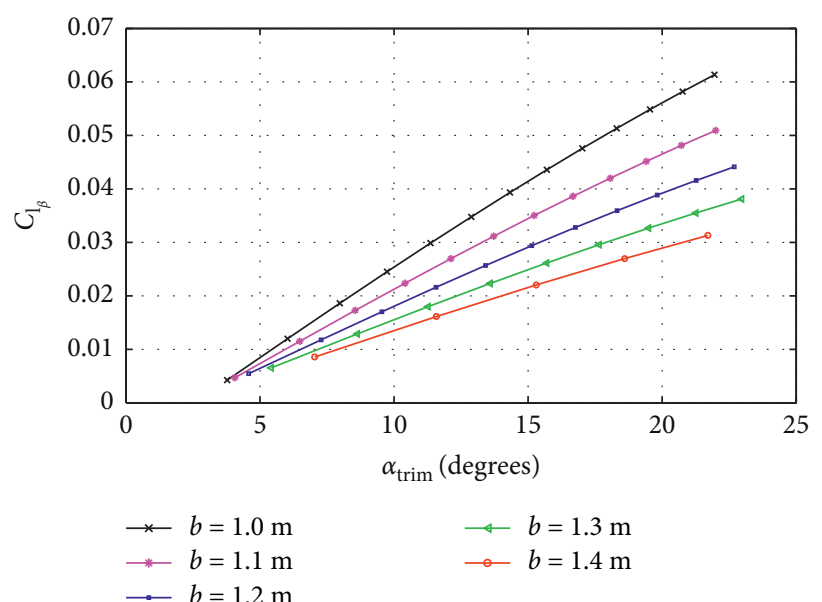

(a)

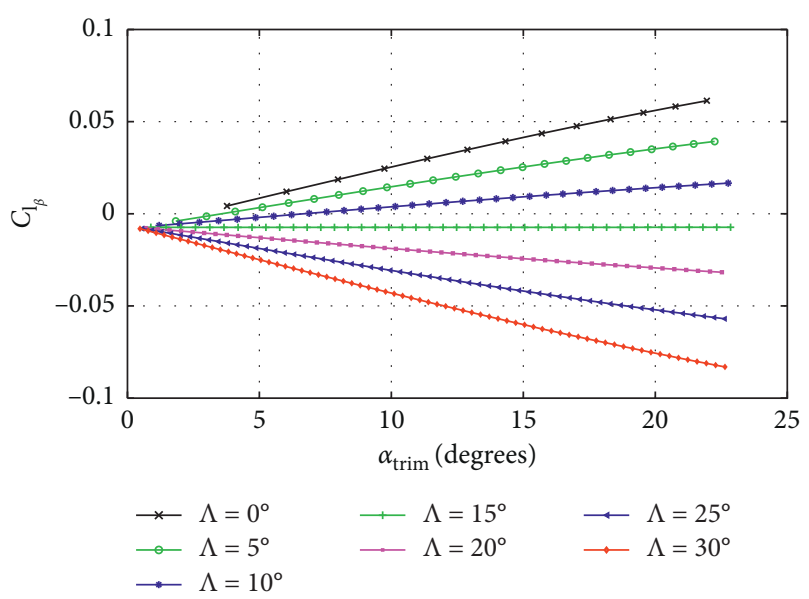

(b)

FIgURE 9: Lateral static stability for wingspan (a) and wing sweep (b) morphing.

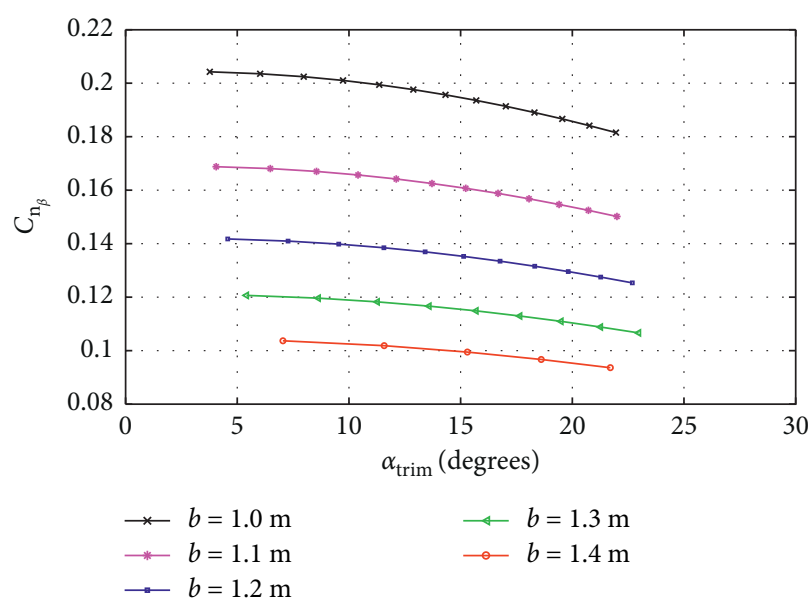

(a)

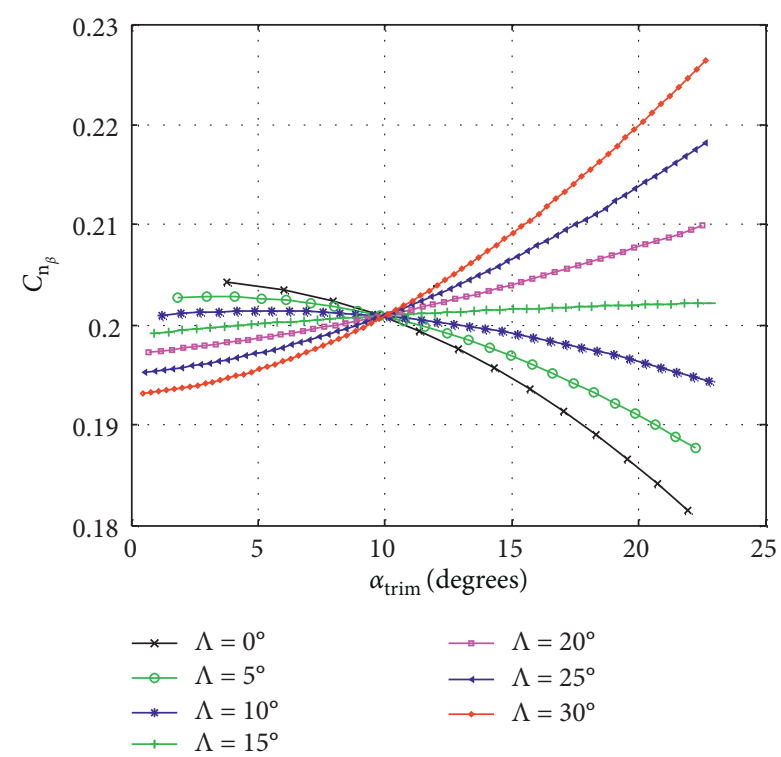

(b)

Figure 10: Directional static stability for wingspan (a) and wing sweep (b) morphing.

work likewise to ensure aircraft lateral stability. Hence, both lateral and directional static stabilities are catered by wing sweep aft morphing.

3.4. Longitudinal Dynamics. Longitudinal dynamic modes in the prestall regime for both morphing schemes are presented in Figures 11 and 12. Figure 11 reflects stable short period modes for both wingspan and sweep morphing schemes and their damping decreases with the increase in trim angle of attack. For wingspan morphing, short period frequency decreases along the wingspan extension (refer to Figure 11(a)). Above $1.2 \mathrm{~m}$ of wing extension, slight frequency augmentation is evident at higher trim angles of attack. Aircraft configuration with wingspan $1.4 \mathrm{~m}$ exhibits overdamped short period mode for lower trim states as indicated by two negative real distinct roots at $7.03^{\circ}$ and $11.5^{\circ}$ of $\alpha_{\text {trim }}$. In terms of flying qualities, the period of oscillation and time to half the amplitude increases with the increase in trim angle of attack for a specific span configuration. For the same trim angle of attack, the increase in span results in higher period of oscillation but does not affect much time to half the amplitude. Wing sweep morphing, however, significantly aggravates short period oscillations at lower trim angles of attack (refer to Figure 11(b)). The period of oscillation and time to half the amplitude increase with the increase in trim angle of attack for a specific sweep configuration. For the same trim angle of attack, the increase in sweep results in reduced time to half the amplitude and period of oscillation. Overall, the short period mode is so 


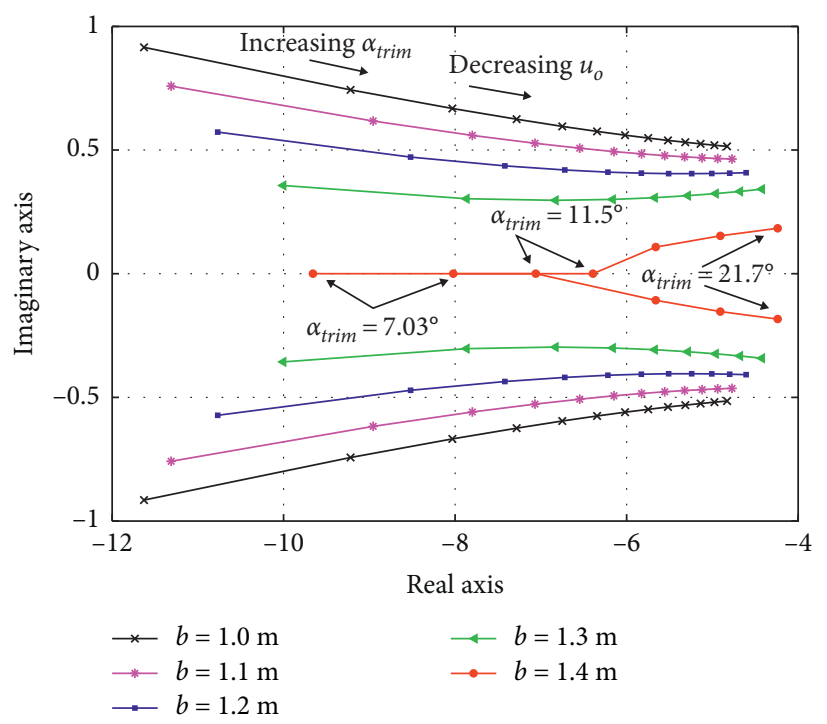

(a)

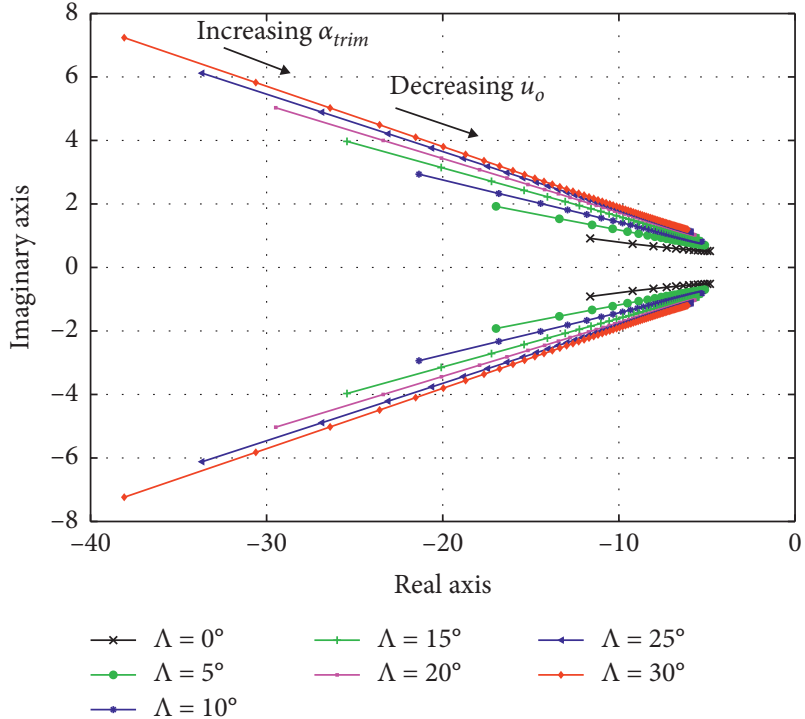

(b)

FIgURE 11: Short period mode for wingspan (a) and wing sweep (b) morphing.

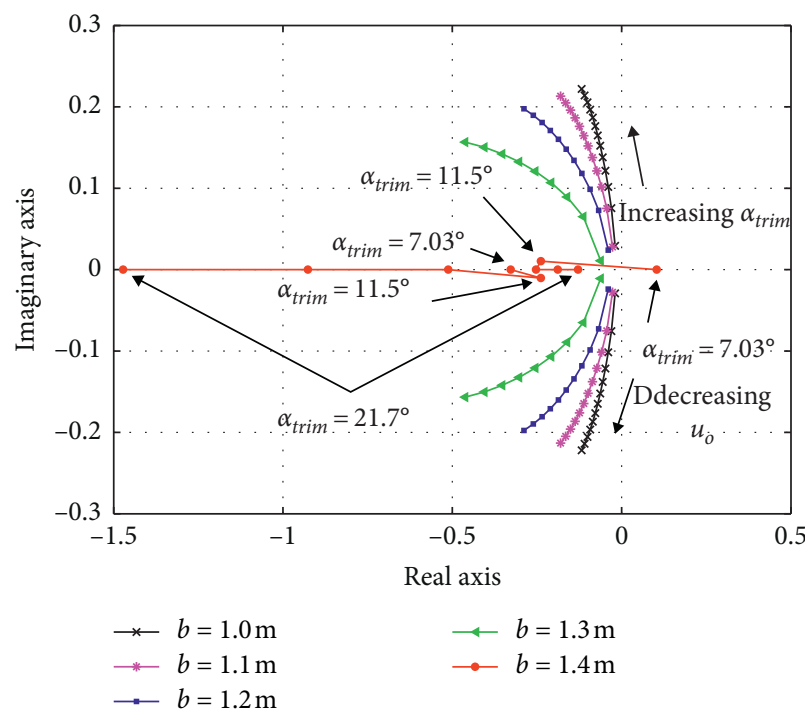

(a)

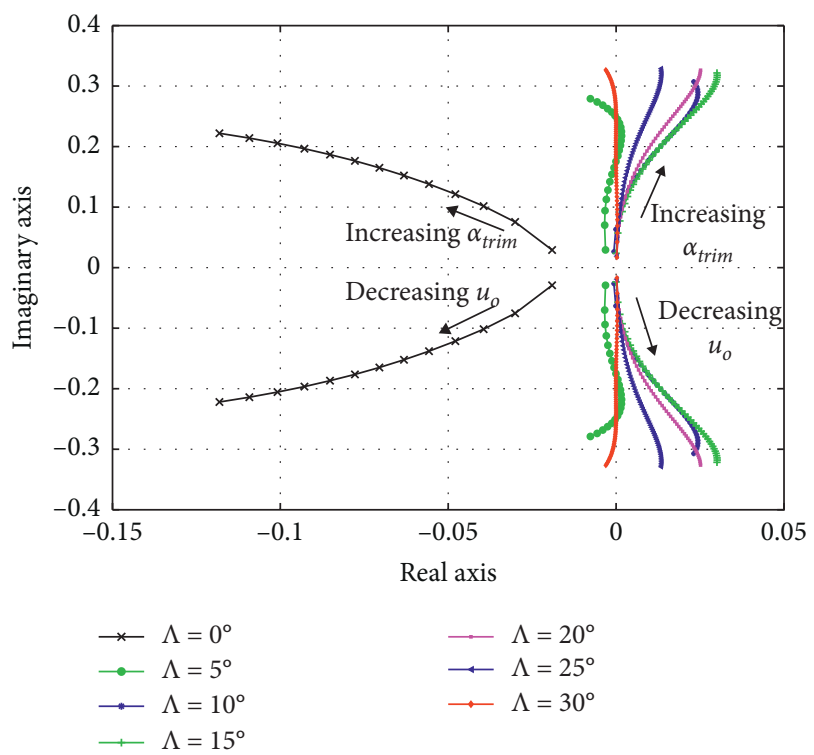

(b)

Figure 12: Long period (phugoid) mode for wingspan (a) and wing sweep (b) morphing.

heavily damped so that span morphing and sweep morphing do not adversely affect flying characteristics. The representative values of longitudinal mode characteristics are shown in Table 3.

Phugoid mode variations for wingspan and sweep morphing are presented by Figure 12. For span-wise morphing, phugoid mode is stable up to $1.3 \mathrm{~m}$ of wing extension (refer Figure 12(a)). Wingspan morphing causes to increase the phugoid damping thereby reducing the phugoid frequency along the increasing trim angles of attack. For $1.4 \mathrm{~m}$ wingspan, aircraft shows unstable phugoid maneuver at $7.03^{\circ}$ of $\alpha_{\text {trim }}$ whereas stable phugoid oscillations appear at $11.5^{\circ}$ of $\alpha_{\text {trim }}$. This configuration shows overdamped phugoid motion for rest of the trim states (afterwards $11.5^{\circ}$ of $\alpha_{\text {trim }}$ ). In terms of flying qualities, the period of oscillation and time to half the amplitude reduces with the increase in trim angle of attack for a specific span configuration. For the same trim angle of attack, the increase in span result in reduced time to half the amplitude, however, do not significantly change period of oscillation (Table 3). Wing sweep morphing substantially deteriorate the phugoid damping as indicated by Figure 12(b). This leads to the unstable phugoid maneuver for wing configurations with sweep angles $10^{\circ}, 15^{\circ}, 20^{\circ}$, and $25^{\circ}$. Eigenvalues 
TABLE 3: Longitudinal mode characteristics.

\begin{tabular}{|c|c|c|c|c|c|c|c|c|}
\hline \multirow[b]{2}{*}{ No. } & \multicolumn{4}{|c|}{ Span morphing } & \multicolumn{4}{|c|}{ Sweep morphing } \\
\hline & $\begin{array}{c}\alpha_{\text {trim }} \\
(\mathrm{deg})\end{array}$ & $\begin{array}{c}\text { Span } \\
\text { configuration (m) }\end{array}$ & $\begin{array}{l}\text { Period } \\
\text { (s) }\end{array}$ & $\begin{array}{l}\text { Time to double }\left(T_{2}\right) / \text { half } \\
\text { amplitude }\left(T_{1 / 2}\right)(\mathrm{s})\end{array}$ & $\begin{array}{c}\alpha_{\text {trim }} \\
(\mathrm{deg})\end{array}$ & $\begin{array}{c}\text { Sweep } \\
\text { configuration (deg) }\end{array}$ & $\begin{array}{l}\text { Period } \\
\text { (s) }\end{array}$ & $\begin{array}{l}\text { Time to double }\left(T_{2}\right) / \text { half } \\
\text { amplitude }\left(T_{1 / 2}\right)(\mathrm{s})\end{array}$ \\
\hline \multicolumn{9}{|c|}{ Short period mode } \\
\hline 1 & 10 & 1 & 10.09 & $0.096\left(T_{1 / 2}\right)$ & 10 & 5 & 6.72 & $0.0912\left(T_{1 / 2}\right)$ \\
\hline 2 & 10 & 1.1 & 11.8 & $0.096\left(T_{1 / 2}\right)$ & 10 & 10 & 5.5 & $0.088\left(T_{1 / 2}\right)$ \\
\hline \multicolumn{9}{|c|}{ Phugoid mode } \\
\hline 1 & 10 & 1 & 50.5 & $14.1\left(T_{1 / 2}\right)$ & 10 & 5 & 35.1 & $290\left(T_{1 / 2}\right)$ \\
\hline 2 & 10 & 1.1 & 51.1 & $10.1\left(T_{1 / 2}\right)$ & 10 & 10 & 31.5 & $53.1\left(T_{2}\right)$ \\
\hline
\end{tabular}

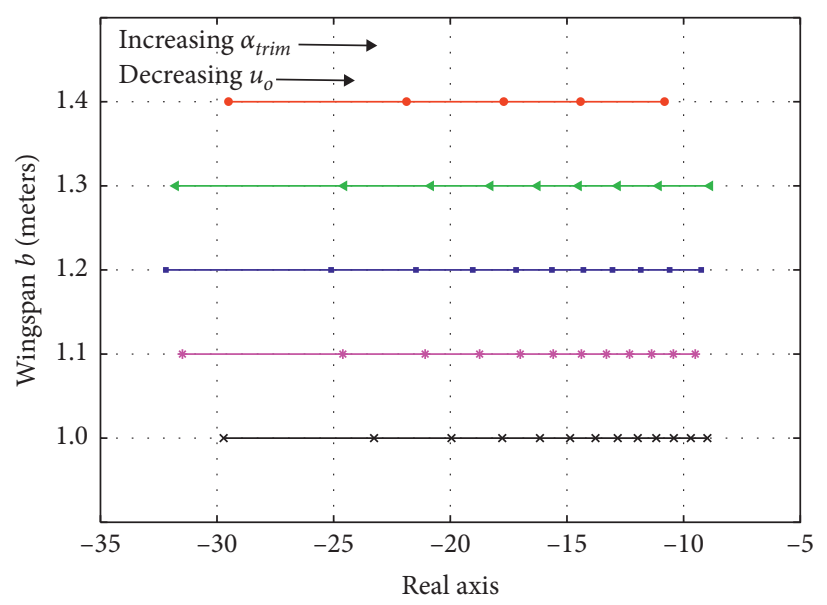

(a)

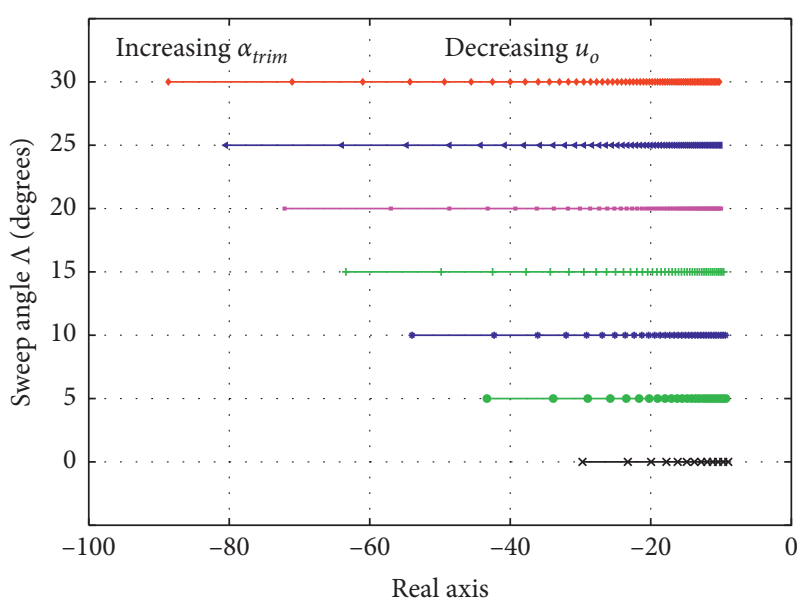

(b)

FIGURE 13: Roll subsidence for wingspan (a) and wing sweep (b) morphing.

migration around imaginary axis pertains to the explicit unstable regions for wing sweep of $5^{\circ}$ (from $10.7^{\circ}$ to $17.4^{\circ}$ of $\alpha_{\text {trim }}$ regime) and wing sweep of $30^{\circ}$ (afterwards $5.6^{\circ}$ of $\alpha_{\text {trim }}$ ). Therefore, the presence of limit cycle type oscillations associated with Hopf bifurcation is likely where the eigenvalues cross the imaginary axis from left-half to the righthalf of complex plane. The period of oscillation and time to half the amplitude reduces with the increase in trim angle of attack for a specific sweep configuration. For the same trim angle of attack, the increase in sweep result in reduced time to half the amplitude as well as period of oscillation. The above analysis reveals that wing sweep morphing has more pronounced effect on aircraft longitudinal dynamics as compared to the wingspan morphing.

3.5. Lateral-Directional Dynamics. Lateral-directional dynamic response of aircraft for both wing morphing schemes is shown in Figures 13-15. Both morphing schemes exhibit dynamically stable roll subsidence and their damping decreases along the increasing trim angles of attack. Wingspan extension trivially affects the roll mode (refer Figure 13(a)) whereas wing sweep morphing reasonably increases the roll damping at lower trim angles of attack (refer Figure 13(b)). The change in span and sweep angle do not significantly affect time to half the amplitude for a specific trim angle of attack.
Figure 14 indicates the unstable spiral mode damping reducing along the increasing trim angles of attack for wingspan and sweep morphing schemes. Variation in wingspan shows least impact on aircraft spiral damping (refer Figure 14(a)) however, wing sweep morphing leans the aircraft towards spiral stability at lower trim angles of attack (refer Figure 14(b)). The change in span and sweep do not significantly affect time to half the amplitude for a specific trim angle of attack. The representative values of spiral mode characteristics are shown in Table 4. This is an undesirable feature identified during dynamic analysis.

Figure 15 compares the stable Dutch roll modes for both wingspan and sweep morphing schemes. Low wingspan configurations manifest comparatively high Dutch roll frequency at lower trim angles of attack as shown in Figure 15(a). Wingspan extension amplifies the attenuation in Dutch roll motion along the increasing trim angles of attack. In terms of flying qualities, the period of oscillation increases with the increase in trim angle of attack for a specific span configuration; however, a benign change is observed in time to half the amplitude. For the same trim angle of attack, the increase in span results in higher period of oscillation; however, it does not affect significantly the time to half the amplitude. Conversely, wing sweep morphing intensifies the Dutch roll motion at lower trim angles of attack whereas its damping and frequency gradually decrease along the ascending trim angles of attack 


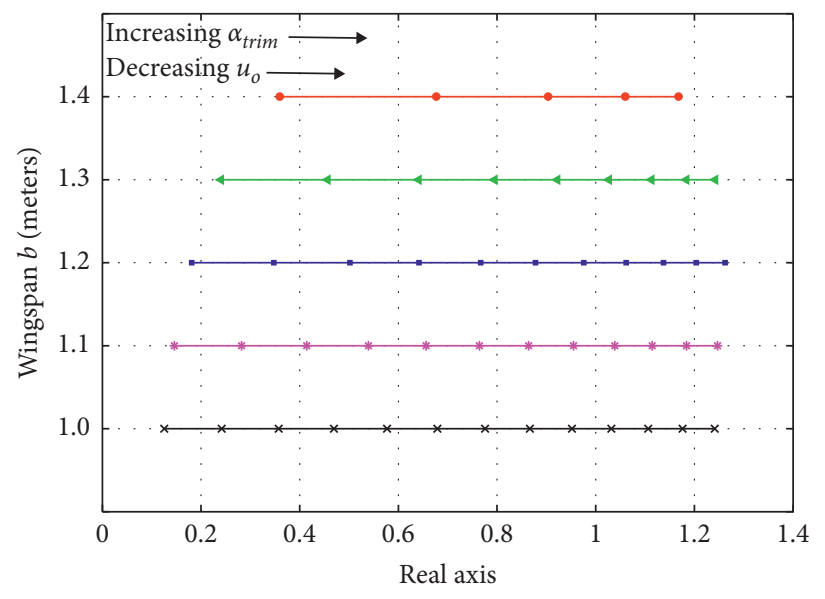

(a)

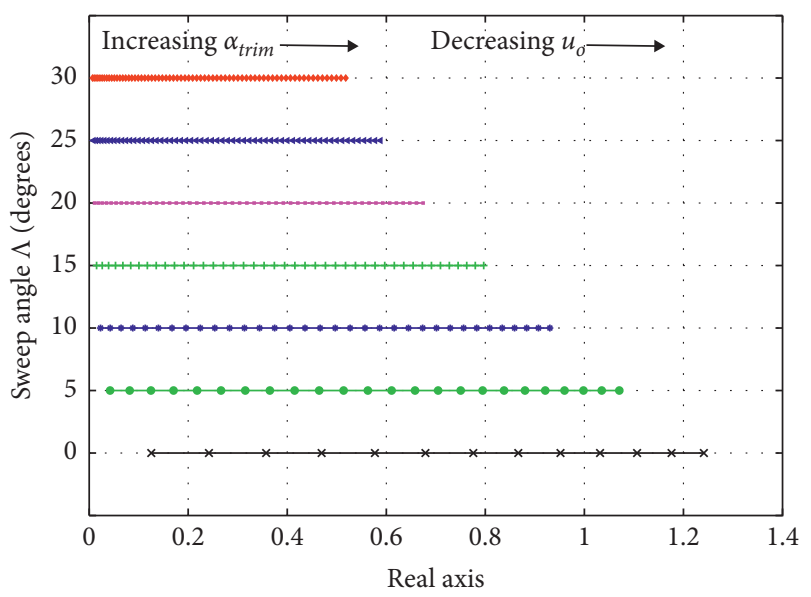

(b)

FIgURE 14: Spiral mode damping for wingspan (a) and wing sweep (b) morphing.

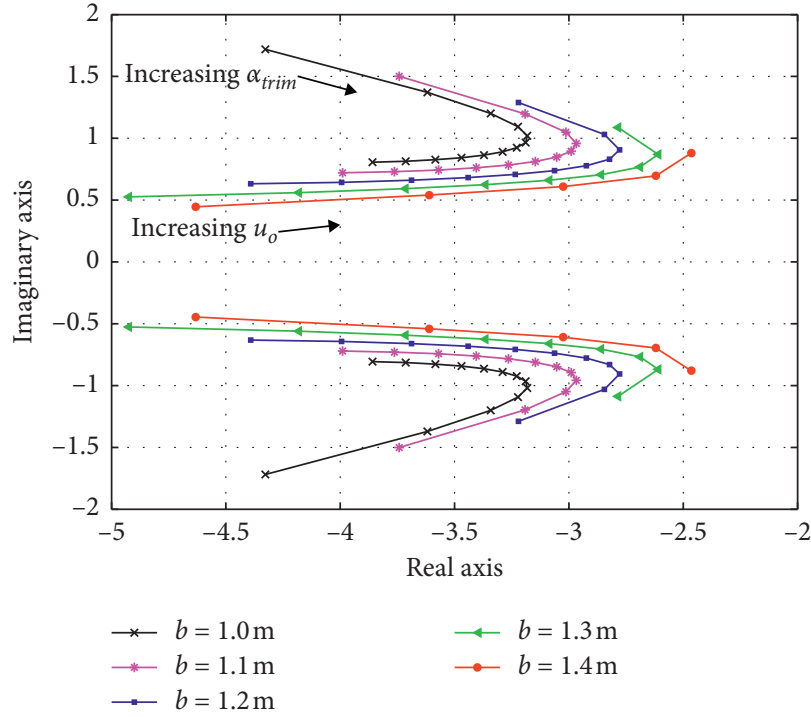

(a)

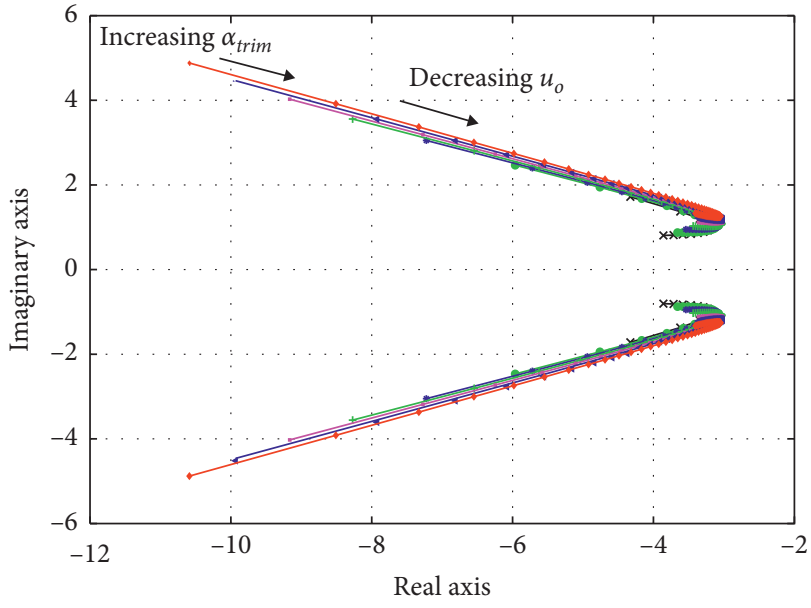

$$
\begin{aligned}
& \rightarrow \Lambda=0^{\circ} \\
& \because \Lambda=5^{\circ} \\
& \rightarrow \Lambda=10^{\circ} \\
& \multimap \Lambda=15^{\circ}
\end{aligned}
$$

\begin{tabular}{|c|c|c|c|c|c|c|c|c|}
\hline \multirow[b]{2}{*}{ No. } & \multicolumn{4}{|c|}{ Span morphing } & \multicolumn{4}{|c|}{ Sweep morphing } \\
\hline & $\begin{array}{c}\alpha_{\text {trim }} \\
(\mathrm{deg})\end{array}$ & $\begin{array}{c}\text { Span } \\
\text { configuration }(\mathrm{m})\end{array}$ & $\begin{array}{l}\text { Period } \\
\text { (s) }\end{array}$ & $\begin{array}{l}\text { Time to double }\left(T_{2}\right) / \text { half } \\
\text { amplitude }\left(T_{1 / 2}\right)(\mathrm{s})\end{array}$ & $\begin{array}{l}\alpha_{\text {trim }} \\
(\mathrm{deg})\end{array}$ & $\begin{array}{c}\text { Sweep } \\
\text { configuration (deg) }\end{array}$ & $\begin{array}{l}\text { Period } \\
\text { (s) }\end{array}$ & $\begin{array}{l}\text { Time to double }\left(T_{2}\right) / \text { half } \\
\text { amplitude }\left(T_{1 / 2}\right)(\mathrm{s})\end{array}$ \\
\hline \multicolumn{9}{|c|}{ Roll subsidence } \\
\hline 1 & 15 & 1 & - & $0.052\left(T_{1 / 2}\right)$ & 15 & 5 & - & $0.05\left(T_{1 / 2}\right)$ \\
\hline 2 & 15 & 1.1 & - & $0.048\left(T_{1 / 2}\right)$ & 15 & 10 & - & $0.05\left(T_{1 / 2}\right)$ \\
\hline \multicolumn{9}{|c|}{ Spiral mode } \\
\hline 1 & 15 & 1 & - & $0.74\left(T_{2}\right)$ & 15 & 5 & - & $0.983\left(T_{2}\right)$ \\
\hline 2 & 15 & 1.1 & - & $0.815\left(T_{2}\right)$ & 15 & 10 & - & $1.14\left(T_{2}\right)$ \\
\hline \multicolumn{9}{|c|}{ Dutch roll } \\
\hline 1 & 15 & 1 & 6.9 & $0.21\left(T_{1 / 2}\right)$ & 15 & 5 & 6.61 & $0.22\left(T_{1 / 2}\right)$ \\
\hline 2 & 15 & 1.1 & 7.7 & $0.22\left(T_{1 / 2}\right)$ & 15 & 10 & 6.3 & $0.22\left(T_{1 / 2}\right)$ \\
\hline
\end{tabular}

(b)

FIGURE 15: Dutch roll mode for wingspan (a) and wing sweep (b) morphing.

TABLE 4: Lateral-directional mode characteristics. 
(refer to Figure 15(b)). The period of oscillation and time to half the amplitude increase with the increase in trim angle of attack for a specific sweep configuration. For the same trim angle of attack, sweep morphing results in insignificant change for time to half the amplitude as well as period of oscillation. The overall lateral-directional dynamics of the aircraft are remarkably governed by the wing sweep morphing whereas span morphing least contributes in altering lateral-directional dynamic response of the aircraft.

3.6. Limitations of the Study. The findings presented in this paper are based on certain limitations:

(a) There can be various novel solutions as well as morphing schemes that can augment flight performance. However, in this work, only two morphing schemes are considered. Utilization of other morphing mechanisms may prove better than the considered approaches.

(b) The aerodynamic modeling is based on Vortex Lattice Method (VLM). VLM cannot capture phenomena related to flow separation at high angles of attack. Similarly, unsteady transitional effects cannot be modeled. Moreover, the thickness effects of lifting surfaces are also neglected in VLM modeling. Therefore, the aerodynamic model used in the present study is of moderate fidelity and restricted to low angle of attack range.

(c) The mathematical evaluation of stability characteristics was made through extensive simulations. The suggested approaches need further hardware implementation and validation through flight demonstration. This might lead to results which can vary from the theoretical findings. Therefore, the benefits estimated to be achieved by morphing configurations in comparison to the fixed configurations, once dovetailed with practical implementation, may show some variations.

(d) The morphing mechanism can only be evoked with some actuations. The actuation cost is an important factor that needs to be modeled during practical implementation. However, since the research presented in this project is of exploratory nature, the actuation energy requirements may be considered at some later stage.

\section{Conclusion}

The current research was conducted to investigate the correlation between wing morphing and aircraft flight dynamics. For this purpose, two underlying morphing schemes (variation in wingspan and sweep angle) are analyzed from stability perspective and flight dynamic characteristics are evaluated for a small-scale morphing capable UAV. Results conclude that the wingspan extension gradually reduces the longitudinal and directional static stability of the aircraft; however, it aids more in lateral stability at higher angles of attack. Wing sweep morphing significantly increases the overall inherent static stability of the aircraft assisting in all three (longitudinal, lateral, and directional) dimensions. Wingspan extension reduces short period frequency and damping while the sweep morphing affects vice versa. Wingspan morphing attenuates phugoid frequency and increases phugoid damping. Sweep morphing, however, acts the other way around. In comparison with span variation, sweep morphing remarkably increases roll subsidence whereas spiral damping is nearly unaffected for both morphing schemes. Dutch roll mode is trivially affected for wingspan variation while significantly aggravated for sweep morphing. Based on trim analysis, it is convincingly suggested that the wingspan morphing is highly favorable toward reducing aircraft trim requirements whereas maneuvering capabilities can be enhanced through wing sweep morphing. Conclusively, the idea of wing morphing as a means for optimizing aircraft versatility in different flight scenarios is appreciated by the preliminary findings of the present work. Although practical realization of a morphing aircraft is demanding, the current study provides an insight into the flight dynamic prospects of various wing morphing schemes and forms a baseline to explore the applied aspects of this research. This, therefore, encourages to investigate other morphologies like wing twist and wing folding.

\section{Nomenclature}

$\begin{array}{ll}b: & \text { Wingspan } \\ C_{(*)}: & \text { Coefficient of } * \\ D: & \text { Drag } \\ g: & \text { Acceleration due to gravity } \\ I_{* *}: & \text { Aircraft moment of inertia w.r.t. } * * \text { axis } \\ L: & \text { Rolling moment } \\ m: & \text { Mass } \\ M: & \text { Pitching moment } \\ N: & \text { Yawing moment } \\ p: & \text { Roll rate } \\ q: & \text { Pitch rate } \\ r: & \text { Yaw rate } \\ u: & \text { Aircraft horizontal velocity } \\ u_{o}: & \text { Aircraft horizontal trim velocity } \\ v: & \text { Aircraft side velocity } \\ w: & \text { Aircraft vertical velocity } \\ X: & \text { Aircraft axial force } \\ Y: & \text { Aircraft side force } \\ Z: & \text { Aircraft normal force } \\ \alpha: & \text { Freestream angle of attack } \\ \alpha_{\text {trim }}: & \text { Trim angle of attack } \\ \beta: & \text { Side slip angle } \\ \theta: & \text { Aircraft pitch attitude } \\ \phi: & \text { Aircraft roll attitude } \\ \Lambda: & \text { Wing sweep angle } \\ \delta_{e}: & \text { Elevator deflection angle } \\ \delta_{e_{\text {trim }}}: & \text { Elevator trim deflection angle } \\ w: & \text { Frequency } \\ \varsigma: & \text { Damping ratio } \\ (): & \text { First-order time derivative } \\ () & \text { Derivative w.r.t. } * . \\ & \\ w_{*} & \end{array}$




\section{Data Availability}

The data can be made available upon request to the corresponding author.

\section{Conflicts of Interest}

The authors declare that they have no conflicts of interest.

\section{References}

[1] A. K. Jha and J. N. Kudva, "Morphing aircraft concepts, classifications, and challenges," in Proceedings of the Smart Structures and Materials 2004: Industrial and Commercial Applications of Smart Structures Technologies, vol. 5388, International Society for Optics and Photonics, San Diego, CA, USA, pp. 213-225, 2004.

[2] I. Dayyani, A. D. Shaw, E. I. Saavedra Flores, and M. I. Friswell, "The mechanics of composite corrugated structures: a review with applications in morphing aircraft," Composite Structures, vol. 133, pp. 358-380, 2015.

[3] D. Lentink and R. de Kat, "Gliding swifts attain laminar flow over rough wings," PLoS One, vol. 9, no. 6, Article ID e99901, 2014.

[4] D. Lentink, U. K. Müller, E. J. Stamhuis et al., "How swifts control their glide performance with morphing wings," $\mathrm{Na}$ ture, vol. 446, no. 7139, pp. 1082-1085, 2007.

[5] I. Chopra, "Review of state of art of smart structures and integrated systems," AIAA Journal, vol. 40, no. 11, pp. 2145-2187, 2002.

[6] Z. Min, V. K. Kien, and L. J. Y. Richard, "Aircraft morphing wing concepts with radical geometry change," The IES Journal Part A: Civil \& Structural Engineering, vol. 3, no. 3, pp. 188-195, 2010.

[7] A. Y. N. Sofla, S. A. Meguid, K. T. Tan, and W. K. Yeo, "Shape morphing of aircraft wing: status and challenges," Materials \& Design, vol. 31, no. 3, pp. 1284-1292, 2010.

[8] X.-Z. Gao, Z.-X. Hou, Z. Guo, R.-F. Fan, and X.-Q. Chen, "Analysis and design of guidance-strategy for dynamic soaring with UAVs," Control Engineering Practice, vol. 32, pp. 218-226, 2014.

[9] J. P. Barnes, "How flies the albatross-the flight mechanics of dynamic soaring," in Proceedings of the SAE Technical Paper, Reno, NV, USA, 2004.

[10] M. Rosén and A. Hedenström, "Gliding flight in a jackdaw: a wind tunnel study," The Journal of Experimental Biology, vol. 204, no. Pt 6, pp. 1153-1166, 2001.

[11] S. Barbarino, O. Bilgen, R. M. Ajaj, M. I. Friswell, and D. J. Inman, "A review of morphing aircraft," Journal of Intelligent Material Systems and Structures, vol. 22, no. 9, pp. 823-877, 2011.

[12] T. A. Weisshaar, "Morphing aircraft systems: historical perspectives and future challenges," Journal of Aircraft, vol. 50, no. 2, pp. 337-353, 2013.

[13] I. Mir, A. Maqsood, S. A. Eisa, H. Taha, and S. Akhtar, "Optimal morphing-augmented dynamic soaring maneuvers for unmanned air vehicle capable of span and sweep morphologies," Aerospace Science and Technology, vol. 79, pp. 17-36, 2018.

[14] J. D. Anderson, Introduction to Flight, McGraw-Hill, Boston, MA, USA, 2005.

[15] J. Blondeau, J. Richeson, and D. J. Pines, "Design, development and testing of a morphing aspect ratio wing using an inflatable telescopic spar," in Proceedings of the AIAA paper, vol. 1718, pp. 7-10, 2003.

[16] I. Mir, A. Maqsood, and S. Akhtar, "Biologically inspired dynamic soaring maneuvers for an unmanned air vehicle capable of sweep morphing," International Journal of Aeronautical and Space Sciences, vol. 19, no. 4, pp. 1006-1016, 2018.

[17] K. S. Kong, Performance and Flight Dynamic Characteristics of Folding-Wing Aircraft, School of Mechanical and Aerospace Engineering, Nanyang Technological University, Singapore, 2009.

[18] Z. W. Chong, Performance and Flight Dynamics Characteristics of a Variable Sweep Wing Aircraft, School of Mechanical and Aerospace Engineering, Nanyang Technological University, Singapore, 2009.

[19] N. Prabhakar, R. J. Prazenica, and S. Gudmundsson, "Dynamic analysis of a variable-span, variable-sweep morphing UAV," in Proceedings of the 2015 IEEE Aerospace Conference, pp. 1-12, Big Sky, MT, USA, 2015.

[20] D. Inman, "Wings: out of the box. Determining actuator requirements for controlled morphing air vehicles-aerodynamic loads," in Proceedings of the DARPA Technology Interchange Meeting, Wright Patterson Air Force Base, Dayton, OH, USA, 2001.

[21] A. Tarnowski and T. Goetzendorf-Grabowski, "Design of morphing wing with surface discontinuity," Proceedings of the Institution of Mechanical Engineers, Part G: Journal of Aerospace Engineering, vol. 232, no. 14, pp. 2638-2650, 2018.

[22] A. Tarnowski, "Morphing wing with skin discontinuity kinematic concept," Aircraft Engineering and Aerospace Technology, vol. 89, no. 4, pp. 535-546, 2017.

[23] A. Maqsood and T. H. Go, "Optimization of transition maneuvers through aerodynamic vectoring," Aerospace Science and Technology, vol. 23, no. 1, pp. 363-371, 2012.

[24] A. Maqsood and T. H. Go, "Multiple time scale analysis of aircraft longitudinal dynamics with aerodynamic vectoring," Nonlinear Dynamics, vol. 69, no. 3, pp. 731-742, 2012.

[25] A. M. Wickenheiser and E. Garcia, "Optimization of perching maneuvers through vehicle morphing," Journal of Guidance, Control, and Dynamics, vol. 31, no. 4, pp. 815-823, 2008.

[26] J. Mestrinho, P. Gamboa, and P. Santos, "Design optimization of a variable-span morphing wing for a small uav," in Proceedings of the 52nd AIAA/ASME/ASCE/AHS/ASC Structures, Structural Dynamics and Materials Conference, p. 2025, Denver, CO, USA, 2011.

[27] A. Maqsood and T. Hiong Go, "Longitudinal flight dynamic analysis of an agile UAV," Aircraft Engineering and Aerospace Technology, vol. 82, no. 5, pp. 288-295, 2010.

[28] I. Mir, H. Taha, S. A. Eisa, and A. Maqsood, "A controllability perspective of dynamic soaring," Nonlinear Dynamics, vol. 94, no. 4, pp. 2347-2362, 2018.

[29] G. B. Gebretekle, D. Haile Mariam, W. Abebe Taye et al., "Half of prescribed antibiotics are not needed: a pharmacist-led antimicrobial stewardship intervention and clinical outcomes in a referral hospital in Ethiopia," Frontiers in Public Health, vol. 8, 2020.

[30] M. I. Friswell and D. J. Inman, "Morphing concepts for UAVs," in Proceedings of the 21st International Unmanned Air Vehicle Systems Conference, Bristol, UK, 2006.

[31] T. A. Weisshaar, "Morphing aircraft technology-new shapes for aircraft design," Technical Report, DTIC Document 2006, NATO, Brussels, Belgium, 2006.

[32] R. Vos, R. De Breuker, R. Barrett, and P. Tiso, "Morphing wing flight control via postbuckled precompressed 
piezoelectric actuators," Journal of Aircraft, vol. 44, no. 4, pp. 1060-1068, 2007.

[33] J. B. Samuel and D. Pines, "Design and testing of a pneumatic telescopic wing for unmanned aerial vehicles," Journal of Aircraft, vol. 44, no. 4, pp. 1088-1099, 2007.

[34] J. Herencia, P. Weaver, and M. Friswell, "Morphing wing design via aeroelastic tailoring," in Proceedings of the 48th AIAA/ASME/ASCE/AHS/ASC Structures, Structural Dynamics, and Materials Conference, p. 2214, Honolulu, HI, USA, 2007.

[35] Q. Wang, Y. Chen, and H. Tang, Mechanism Design for Aircraft Morphing Wing, AIAA, Honolulu, HI, USA, 2012.

[36] B. L. Stevens and F. L. Lewis, Aircraft Control and Simulation, Wiley, New York, NY, USA, 2003.

[37] T. R. Yechout, Introduction to Aircraft Flight Mechanics: Performance, Static Stability, Dynamic Stability, and Classical Feedback Control, American Institute of Aeronautics and Astronautics, Reston, VA, USA, 2003.

[38] J. J. Bertin and M. L. Smith, Aerodynamics for Engineers, Pearson, London, UK, 1998.

[39] J. Katz and A. Plotkin, Low-speed Aerodynamics, Cambridge University Press, Cambridge, UK, 2001.

[40] A. Deperrois, "Guidelines for XFLR5 V6. 03," 2011.

[41] A. Deperrois, "XFLR5,” 6.30 ed, 2016.

[42] B. Etkin and L. D. Reid, Dynamics of Flight: Stability and Control, Wiley, New York, NY, USA, 1996.

[43] R. C. Nelson, Flight Stability and Automatic Control, WCB/ McGraw Hill, New York, NY, USA, 1998.

[44] M. Drela, Flight Vehicle Aerodynamics, MIT Press, Cambridge, MA, USA, 2014.

[45] T. Goetzendorf-Grabowski, E. Marcinkiewicz, and C. Galinski, "Comparison of traditionally calculated stability characteristics with flight test data of PW-6U sailplane," in Proceedings of the Presented at the 4th CEAS Air \& Space Conference, Linkoping, Sweden, 2013.

[46] T. Goetzendorf-Grabowski and T. Antoniewski, "Three surface aircraft (TSA) configuration - flying qualities evaluation," Aircraft Engineering and Aerospace Technology, vol. 88, no. 2, pp. 277-284, 2016. 